HeWamed

\title{
Für Verbandsmitglieder zum Sonderpreis: LED.F Polymerisationslampe
}

- LED-Polymerisationslampe mit neuester Technologie

- Blaues Licht mit einer Wellenlänge von 420nm - 480nm

- Ladestation mit Radiometer

- Lichtleistung bis $1800 \mathrm{~mW} / \mathrm{cm}^{2}$

- Überprüfung und Berechnung der Lichtintensität durch integrierten Mikroprozessor und Radiometer

- 3 Programme für alle Indikationen (Veneer, Bracket, Füllungen, Fissurenversiegelung, pulpennahes Polymerisieren, Bonding-Systeme usw.)Turbo Mode, Normal Mode, Low Mode

Als Ersatzteile erhältlich: Akku und Lichtleiter

Normalpreis: 310,- Euro

Sonderpreis für Verbandsmitglieder: 241,- Euro

Nutzen Sie dieses Angebot und bestellen Sie Ihre LED.F

Polymerisationslampe mit Hilfe des Service-Coupons auf der nächsten DFZ-Seite oder unter www.dynadent.de.

Preise zzgl. MwSt. und 5,- Euro Versand
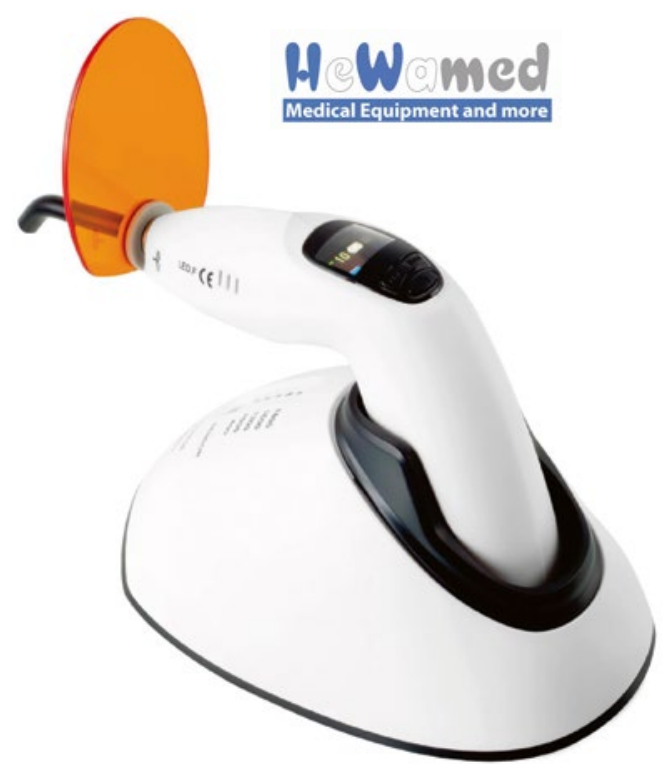

Hier steht eine Anzeige.

黛 Springer 